профессионалы, и они не должны выполнять те же виды работ, что и опытные учителя, без поддержки со стороны соответствующих образовательных структур. Начинающему учителю необходимо время от трех до четырех лет, чтобы усвоить необходимые компетенции, и еще несколько лет, чтобы достичь профессионализма.

Главой государства Н.Назарбаевым в своих Посланиях народу Казахстана обозначена цель формирования уникальной отечественной системы образования. Одной из важных задач достижения данной цели является модернизация методик преподавания и активное развитие онлайн-систем образования [1], а «результатом обучения школьников должно стать овладение ими навыками критического мышления, самостоятельного поиска и глубокого анализа информации» [2]. По своей сути система образования является целостной, динамичной. Ее уровни развиваются в органической и гармоничной связи друг с другом. Система повышения квалификации педагогических работников, являясь частью дополнительного образования, выполняет обслуживающую функцию для всех уровней системы непрерывного образования. То есть, развитие систем дошкольного воспитания и обучения, среднего образования, технического и профессионального, высшего и послевузовского образования напрямую связано и зависит от системы повышения квалификации, так как главными движущими силами всех уровней является потенциал педагогических кадров [3]. Мировой опыт свидетельствует, что успеха достигают те образовательные реформы, в центре которых - материальные и моральные вложения непосредственно в учителя. Постоянное повышение квалификации, статус педагога в обществе - константа успеха ученика, школы, системы [4]. В Казахстане на сегодняшний день параллельно реализуются две программы повышения квалификации педагогических работников:

- $\quad$ краткосрочные (двухнедельные), разрабатываемые АО «Национальный центр повышения квалификации «Өрлеу»;

- уровневые программы (трехмесячные), разработанные ЦПМ АОО «Назарбаев интеллектуальные школы» совместно с Факультетом образования Кембриджского университета.

$$
\text { *** }
$$

1. «План Нации - 100 конкретных шагов. Современное государство для всех». Астана, 2015 г.

2. Закон Республики Казахстан «Об образовании» от 27 июля 2007 года № 319 -III (с изменениями и дополнениями по состоянию на 24.11.15 г.)

3. Государственная программа развития образования Республики Казахстан на 2016-2019 годы, утв. Указом Президента РК 1.03.2016 г. №205.

4. Агеева, И.А. Успешный учитель: тренинговые и коррекционные программы / И.А. Агеева. - СПб.: Речь, 2007. - 208 с.

5. Антонюк В.И. Инновации и психологический барьер //Психологические аспекты управления /Под ред. Ф.М.Русинова, В.И. Антонюка. М.: Экономика, 1984. 160 с.

6. Лобанов, А.А. Основы профессионально-педагогического общения / А.А.Лобанов. - М.: Издательский центр «Академия», 2004. - 192 с.

\title{
Котченко Ю.В. \\ Влияние динамических движений на результат выступления в спортивном скалолазании
}

Севастопольский государственный университет (Россия, Севастополь)

doi: $10.18411 / / j-31-08-2017-24$

idsp: 000001:lj-31-08-2017-24

\section{Аннотация}

В статье рассматривается влияние высокоинтенсивных динамических движений на результат прохождения соревновательной трассы. Анализируются показатели высококлассных спортсменок.Установлено, что степень связи с результатом на трассах 
высшей категории составляет $\mathrm{r}=0,25, \mathrm{p}<0,001$, что требует полной готовности спортсменки к выполнению трех таких движений.

Ключевые слова: скалолазание, соревнования, эффективность выступления, динамические движения.

Структура соревновательного процесса в спортивном скалолазании включает в себя ряд постоянно действующих факторов, оказывающих влияние на результат, непосредственно в ходе прохождения соревновательной трассы. Степень связи данных факторов с результатом различна, иногда очень мала, но в зоне предельной нагрузки, на трассах максимально высокой категории, они могут сыграть, и зачастую играют, решающую роль. Изучение закономерностей поведения таких влияющих факторов, может способствовать повышению эффективности спортивного выступления.

В период с 2012 по 2016 гг., было проведено исследование характера связи и степени влияния динамических движений на результат прохождения трассы, на крупных международных соревнованиях в сложном лазании среди женщин.В анализе использовались данные, полученные в ходе 1216 индивидуальных стартов высококлассных спортсменок на 39 этапах кубка и 3 чемпионатах мира[1].При обработке и анализе данных применялись методы корреляционного и регрессионного анализа. Используемые программы: Kinovea 0.8.24,Statistika 10.

При учете динамических движений (q), рассматривались только высокоинтенсивные движения, когда спортсменка, для достижения удаленной зацепки, резко выталкивает себя с помощью рук и ног с исходной позиции, и в процесс движения включается все туловище. Критерием, характеризующим принадлежность движения к динамическому ряду, служит низкая вероятность возвращения на исходную зацепу, после попытки перехвата.

Часто, потребность в динамике, вызвана спецификой конкретного участка трассы, вынуждающего спортсменку к активным действиям. Но нередки случаи, когда одно и то же место на трассе, часть спортсменок проходит, используя динамическое движение, в то время как соперницы, достают удаленный зацеп в статике. Обоснованность применения нужного действия в той или иной соревновательной ситуации, определяется спортсменкой непосредственно перед выполнением движения, а основанием принятия выбранного решения,является объективная оценка сложившихся условий и личных субъективных ощущений.

На квалификационном этапе соревнований,средний показатель таких движенийсоставляетq $=0,8$, и подтверждает нежелание спортсменок использовать динамические перехваты. С другой стороны, в силу специфики отборочной трассы или индивидуальных морфологических признаков спортсменки, прохождение конкретного отрезка маршрута может быть достаточно жестко обусловлено выполнением именно такого типа движения. Получаемое противоречие находит отражение и в характеристиках фактора: при узком интервале (подавляющая часть значений сосредоточена в интервале от 0 до 2), наблюдается высокая величина стандартного отклонения: $\sigma=1$.

Исследования показали отсутствие сколь либо значимой связи между q-фактором и итоговым результатом на отборочном этапе: $\mathrm{r}=-0,02$. Здесь следует заметить, чтоэто еще не означает полную и постоянную независимость двух признаков, и требует дополнительного анализа. 


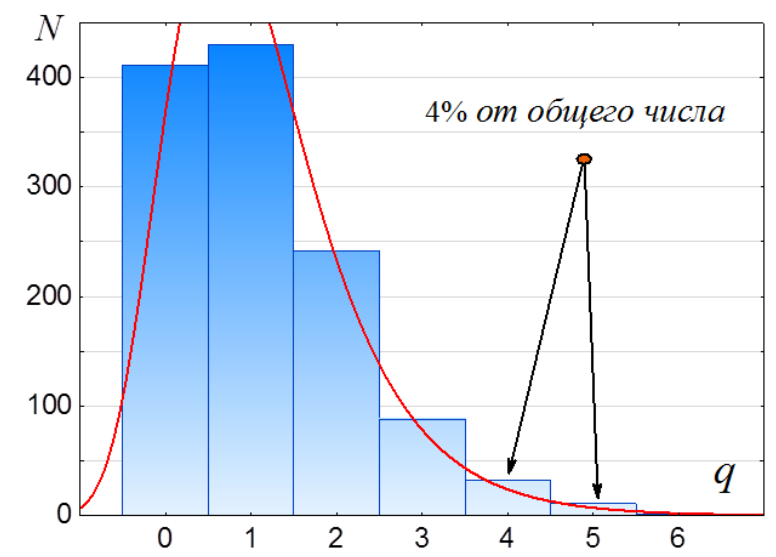

Рис. 1. Гистограмма распределения динамических движений

На полуфинальных и финальных трассах, как и в квалификационных стартах,наиболее «модным»остается показатель в одно высокоинтенсивное динамическое движение на трассе (рисунок1). Спортсменки все также стараются без необходимости не предпринимать никаких рискованных действий, ведь ошибка может стоить очень дорого.Примерно 30\% спортсменок, за время выступления ни разу не используют подобные движения на полуфинальных и финальных трассах. Показатели в 4или5 движений встречаются очень редко: $4 \%$ от общего количества стартов.

Связь с q-фактора с результатом на полуфинальных и финальных трассахвозрастаетдо $\mathrm{r}=0,25, \mathrm{p}<0,001$ и становится достаточно устойчивой, но все же находится в низкой зоне.

Обычно, динамические движения способствуют прохождению трудных участков трассы, и это подтверждает положительный коэффициент корреляции, но в отдельных случаях играют резко негативную роль. Анализ поведения спортсменок в тех местах трассы, где они поставлены перед необходимостью выполнения таких действий, позволил установить закономерности внутреннихсвязей q-фактора в системе соревновательного процесса, и сделать ряд важных практических заключений.

Спортсменки, занимающие более высокие места на соревнованиях, чаще «динамят» для достижения удаленного зацепа. Так, на полуфинальных трассах, средний показатель первой восьмерки лидеров составляет $q=1,3$; а на финальных вырастает еще больше, и доходит до $\mathrm{q}=1,5$. Т.е. лидирующая группа спортсменок, например, на полуфинальных трассах, выполняет по 3 - 5 динамических движений в 15\% стартов, что примерно в 1,5 раза выше, чем у основной группы соперниц. И как мы видим (рис. 2), такие действия, хоть и в небольшом объеме, но все же несут положительный эффект и способствуют более высоким результатам. Это подтверждает необходимость включения данного элемента лазания в тренировочную программу спортсменки.

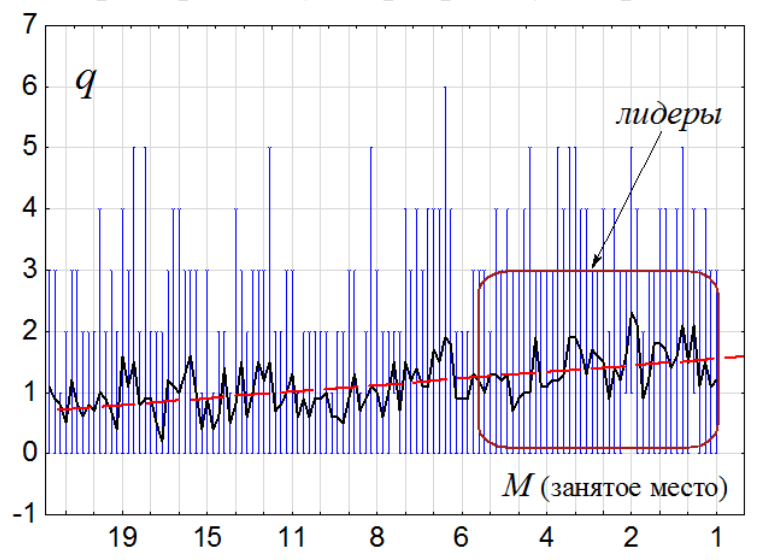

Рис. 2. Рост динамических движений в зависимости от занятого места 
С другой стороны, анализ характеристик q-фактора с учетом других влияющих компонент соревновательного процесса [2], показал, что его прямой вклад в результат очень мал: $\beta q=0,0004$, так же как и коэффициент частной корреляции: $\mathrm{rq}=0,013$. Выход из сложившегося противоречия, видится во включении динамических движений в группу точечно влияющих факторов, способных при определенных условиях, в конкретный момент выступления, оказать существенное воздействие на итоговый результат. Механизм такого точечного влияния в настоящее время не изучен и нуждается в дальнейших исследованиях.

Выводы. Фактор динамического движения по своей природе является стохастическим, и не оказывает заметного воздействия на итоговый результат на этапе отборочных стартов:r $=-0,02$. В то же время, на полуфинально-финальном этапе соревнований степень его влияния возрастает: $\mathrm{r}=0,25, \mathrm{p}<0,001$, что требует постоянной готовности спортсменки к выполнению нескольких (до 3-х) таких движений на трассе.

$$
\text { **** }
$$

1. Worldcompetitions [Электронныйресурс] // InternationalFederationofSportClimbing. - Режимдоступа: http://www.ifsc-climbing.org/

2. КотченкоЮ.В. Системноеисследованиепоказателей, влияющих на спортивный результат в скалолазании/ Ю.В. Котченко // Вестник спортивной науки. - 2016. - № 2 - С. 14 - 17.

\section{Кучеренко Л.В.}

Пример установления междисциплинарных связей физики в вузе

Дальневосточный государственный технический рыбохозяйственный университет (Россия, Владивосток)

doi: $10.18411 / \mathrm{j}-31-08-2017-25$

idsp: 000001:lj-31-08-2017-25

\section{Аннотация}

В работе приведён пример установления междисциплинарных связей физики с другими дисциплинами учебного плана бакалавриата по направлению 15.03 .02 «Технологические машины и оборудование», используя компетентностный подход.

Ключевые слова: междисциплинарные связи, физика, компетентностный подход.

В настоящее время всё больше осознаётся важность интегративных междисциплинарных связей в процессе подготовки специалистов, необходимость обеспечения интегративного характера преподавания дисциплин всех блоков (гуманитарных, общепрофессиональных, естественно - научных, предметных) для повышения качества профессионального образования[1].

В современных условиях одним из ведущих направлений модернизации профессионального образования является формирование основы профессиональной подготовки студентов технического вуза при изучении естественнонаучных дисциплин[2].

Важнейшей задачей вузовского образования является выработка подхода, который позволял студенту видеть глубокую взаимосвязь между всеми изучаемыми предметами, как общеобразовательными так и специальными, а также связь между изучаемыми дисциплинами и будущей профессией[3].

Целью настоящей работы являлось выявление междисциплинарных связей физики с другими дисциплинами учебного плана на примере подготовки бакалавров по направлению 15.03.02 «Технологические машины и оборудование» в Дальрыбвтузе, используя компетентностный подход.

Требования к выпускнику, освоившему программу бакалавриата, устанавливает ФГОС ВО по соответствующему направлению. Автор выбрал профессиональные 